\title{
Effects of a Cylinder Liner Microstructure on Lubrication Condition of a Twin-Land Oil Control Ring and a Piston Skirt of an Internal Combustion Engine
}

Koji Kikuhara ( $\square$ kikuhara@mit.edu )

Massachusetts Institute of Technology https://orcid.org/0000-0001-5287-9588

Philipp S Koeser

Rolls-Royce Solutions

Tian Tian

Massachusetts Institute of Technology

\section{Research Article}

Keywords: Engine Tribology, Surface Roughness, Surface Structure, Surface Texturing, Dimple, Oil Control Ring, Piston Skirt

Posted Date: September 23rd, 2021

DOl: https://doi.org/10.21203/rs.3.rs-905301/v1

License: (c) (1) This work is licensed under a Creative Commons Attribution 4.0 International License.

Read Full License

Version of Record: A version of this preprint was published at Tribology Letters on December 10th, 2021. See the published version at https://doi.org/10.1007/s11249-021-01546-3. 


\title{
Effects of a Cylinder Liner Microstructure on Lubrication Condition of a Twin-Land Oil Control
}

\section{Ring and a Piston Skirt of an Internal Combustion Engine}

Koji Kikuhara $^{1 *}$, Philipp S. Koeser ${ }^{2}$, and Tian Tian ${ }^{1}$

${ }^{1}$ Department of Mechanical Engineering and Sloan Automotive Laboratory, Massachusetts Institute of Technology, Cambridge, MA 02139, USA

${ }^{2}$ Rolls-Royce Solutions GmbH, Maybachplatz 1, 88045 Friedrichshafen, Germany

* Corresponding author: kikuhara@mit.edu

\begin{abstract}
It is hypothesized that the sliding surface structures improve the lubrication condition by forming an oil sump on the sliding surface, redistributing the oil, and trapping wear debris. For these reasons, the sliding surface structures have been used as a friction reduction method for a long time. However, how to optimize the sliding surface structure is still controversial. In this work, effects of microstructure laid on the cylinder liner of an internal combustion engine on twin-land oil control ring (TLOCR) and piston skirt lubrication condition were investigated by comparing friction between the conventional fine-honed liner (CFL) and the microstructured liner (MSL) which was made based on the CFL. As a result of the friction measurement using a floating liner engine, it was found that the microstructure improved lubrication condition by reducing hydrodynamic friction. On the other hand, the result showed there was a possibility that the microstructure deteriorated friction depending on the engine operating conditions.
\end{abstract}

Keywords: Engine Tribology, Surface Roughness, Surface Structure, Surface Texturing, Dimple, Oil Control Ring, Piston Skirt

\section{Declarations}

\section{Funding}

This work was sponsored by Daimler and the Consortium on Lubrication in Internal Combustion Engines in the Sloan Automotive Laboratory, Massachusetts Institute of Technology. The consortium members were Mahle, Rolls-Royce Solutions, Shell, Toyota, Volkswagen, Volvo Trucks, and Weichai Power.

\section{Conflicts of interest/Competing interests (include appropriate disclosures)}

Not applicable

\section{Availability of data and material (data transparency)}

Not applicable

\section{Code availability (software application or custom code)}

Not applicable 


\section{Authors' contribution}

All authors contributed to the study conception and design. Material preparation, data collection and analysis were performed by Koji Kikuhara, Philipp Koeser and Tian Tian. The first draft of the manuscript was written by Koji Kikuhara and all authors commented on previous versions of the manuscript. All authors read and approved the final manuscript.

6. Ethics approval (include appropriate approvals or waivers)

Not applicable

7. Consent to participate (include appropriate statements)

Not applicable

8. Consent for publication (include appropriate statements)

Not applicable 


\section{Introduction}

Downsizing the internal combustion engines to meet the fuel-consumption and $\mathrm{CO} 2$ regulations results in higher thermal load in the engines. These operating conditions put the sliding parts, in particular pistons and piston rings, under harsh lubrication condition. With the requirement of high reliability to internal combustion engines, increasing durability is as important as the decrease of $\mathrm{CO}_{2}$ emissions. Reducing friction of engines by improving the lubrication conditions is an effective way to achieve both reduction of $\mathrm{CO}_{2}$ emissions and engine durability.

Piston ring pack and piston skirt are the major contributors of mechanical losses in internal combustion engines [1]. Therefore, reduction of the piston ring and the piston skirt friction is important. The piston ring pack in a passenger car engine generally consists of three rings namely, the top ring, the second ring, and the oil control ring. The top ring's main functions are to seal the combustion chamber gas and to control blowby. The oil control ring, which is set to the bottom of the ring pack, controls most of the oil supply to the upper part of the piston [2-4]. The second ring usually combines both function of gas sealing and controlling of lubrication oil. A twin-land oil control ring (TLOCR) consists of two parts. One is a steel ring, and the other is a coiled spring. A TLOCR has two narrow contact faces whose profile is flat, which combining with the relatively high ring tension to ensure conformability at the structure level, provides high specific pressure in the contact surface to maintain thin oil film thickness. As a result, oil control ring can contribute over $50 \%$ of the piston ring pack friction [5]. Therefore, the geometric relationship between the TLOCR contact face and the roughness of the cylinder liner surface is important when focusing on the TLOCR's lubrication condition $[6,7]$.

A piston has a barrel shape in the skirt part along the sliding direction. This shape helps to generate hydrodynamic pressure when the piston is running on the oil film. However, a combination of large side force and insufficient oil film can elevate the skirt friction.

To improve the lubrication condition of an engine, application and/or optimization of a surface structure has been widely considered. Here, in this paper, the term surface structure refers to surface roughness and surface texturing. The surface texturing includes grooves by cross hatching on the cylinder surface and dimples of various shapes and sizes. There are mainly five basic beneficial effects of surface texturing [8]:

(1) Capturing wear particles in the texture (debris trapping effect),

(2) Increasing dynamic fluid pressure thus improving the overall load-carrying capacity (micro-hydrodynamic effect),

(3) Drawing additional lubricant into the contact area when the supply pressure in excess of the lubricant cavitation pressure (inlet suction effect),

(4) Storing and supplying lubricant to the contact area (oil storage effect),

(5) Under mixed to dry friction, textures lower the overall contact area and thus friction.

As for the application of texturing to engine parts, Yamasaka et.al. adopted dimple texturing to bottom half 
of the top ring and investigated effects on the friction loss under the fired condition [9]. The results indicated that the dimple texturing help to improve lubrication condition. On the other hand, Urabe et.al. investigated effects of dimples on the cylinder liner on the piston ring friction by using a rig tester [10,11]. The results showed that dimple liner reduced the hydrodynamic friction effectively. However, this result did not include effects on the piston skirt and influence of the fired condition.

This paper aims to study the effects of the microstructure laid on the cylinder liner on the TLOCR and the piston skirt lubrication. Lubrication conditions were evaluated by comparing friction measurement result between the conventional honed liner and the microstructured liner. Friction measurements were performed using a floating liner engine both under motored and fired conditions.

\section{Experimental method}

\subsection{Experimental conditions}

To investigate the effects of the microstructure on friction, engine experiments under motored and fired conditions were performed. The motoring experiments aims to investigate lubrication condition of the twin-land oil control ring (TLOCR) alone. The firing experiments aims to investigate effects of actual operating conditions on the friction of the piston system. The cylinder temperature and the lubrication oil temperature were controlled for all the tests. For the motored conditions, both the cylinder liner and oil temperature were set to $80 \pm 1{ }^{\circ} \mathrm{C}$. For the fired conditions, the cylinder temperature was set to $100 \pm 1{ }^{\circ} \mathrm{C}$, and the oil temperature to $85 \pm 1{ }^{\circ} \mathrm{C}$. The experiments were conducted at $100,200,300,400,500,600,700$, $800,900,1000,1250$ and $1500 \mathrm{rpm}$ for the motored conditions, and 1000, 1500 and $2000 \mathrm{rpm}$ for the fired conditions. The engine load conditions were 4.0 and 8.0 bar indicated mean effective pressure (IMEP) for the fired conditions.

\subsection{Test pieces for the experiments}

Figure 1 shows the 3D surface topography image of the conventional fine-honed liner (CFL) and the microstructured liner (MSL). The MSL was made based on the CFL. Therefore, surface roughness of the honed portion is the same as the CFL's. The Plateau roughness is $0.75 \mu \mathrm{m} \mathrm{Ra}$. The microstructure was added on the liner surface by machining in the final process [12]. The shape of the microstructure is a dimple that is long in the circumferential direction. Figure 2 shows the geometry of the microstructure. The length of the dimple in circumferential direction is $0.9 \mathrm{~mm}$, the width in sliding direction is $90 \mu \mathrm{m}$, and the depth is $7 \mu \mathrm{m}$. The circumferential distance between dimples is $1.5 \mathrm{~mm}$ and the axial distance is $0.3 \mathrm{~mm}$. The microstructure was laid on the whole liner surface including the top dead center of the top ring. Table 1 shows the specifications of the piston used for the experiments. The friction measurement under motored conditions aimed to evaluate the TLOCR's friction alone. Therefore, the piston with small skirt diameter was used to provide negligible contribution to the total friction. Also, experiments were conducted without the engine head for the same reason. Figure 3 shows the comparison of the friction mean effective pressure 
(FMEP) between the MSL and the CFL with piston alone. The small piston still has some friction. However, there is no difference between different cylinder liners. It was considered that oil film is thick enough and the friction behavior of the piston skirt was not affected by the surface structure. Therefore, the evaluation of the lubrication condition of TLOCR affected by the cylinder surface properties was performed using the friction measurement results which includes the piston skirt friction. As for the fired conditions, two pistons were used for the experiments. One general piston skirt with machine marks, which roughness is $2.38 \mu \mathrm{m}$ $\mathrm{Ra}$, and another piston with smooth skirt roughness of $0.54 \mu \mathrm{m} \mathrm{Ra}$. Both pistons have the same piston skirt profile and cold clearance.

Table 2 shows the specifications of the piston ring pack. The land width of the TLOCR is 0.085 $\mathrm{mm}$. The piston ring tensions of the top ring, second ring, and oil ring are $9.4 \mathrm{~N}, 10.3 \mathrm{~N}$, and $19.5 \mathrm{~N}$, respectively. As for the lubricating oil, $0 \mathrm{~W}-20$ grade oil was used.

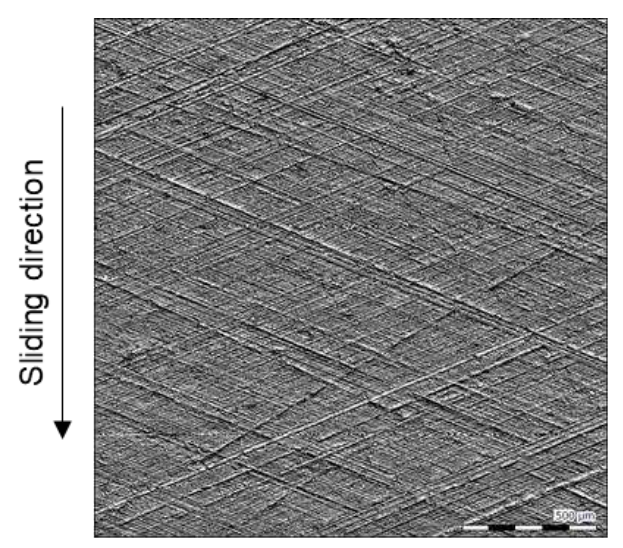

(a) Conventional fine-honed liner (CFL)

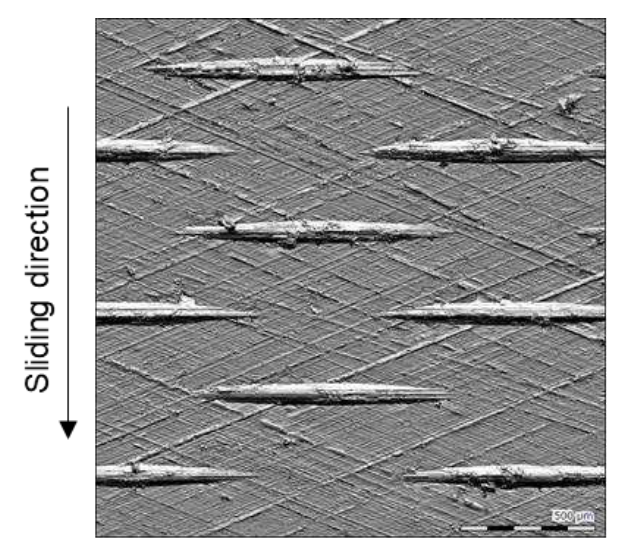

(b) Microstructured liner (MSL)

Fig. 1 3D surface topography image of the cylinder surfaces

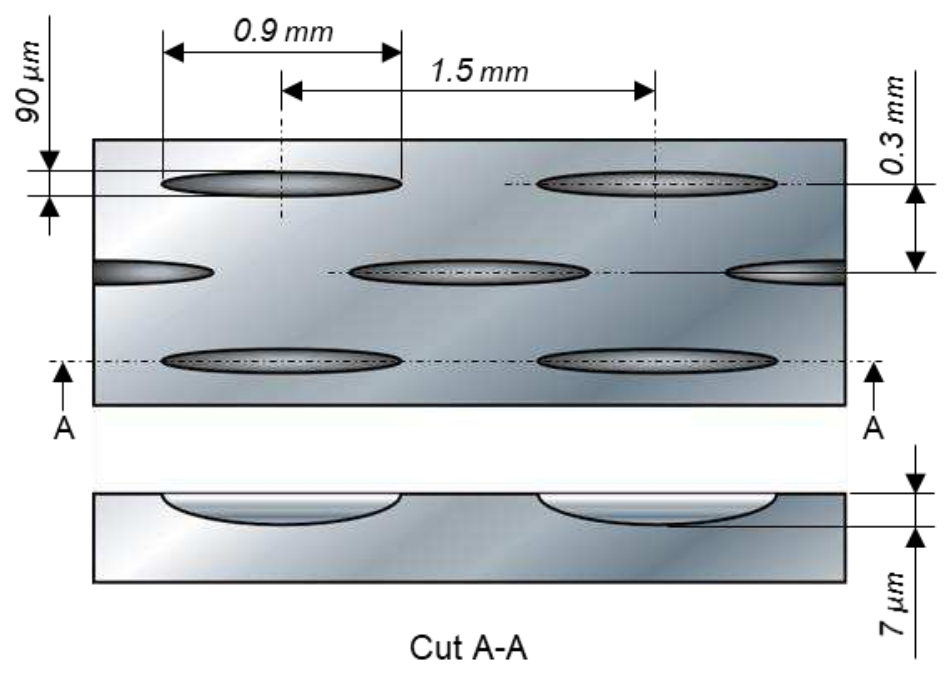


Fig. 2 Geometry of microstructure

Table 1 Specifications of the pistons

\begin{tabular}{lcccc}
\hline \multicolumn{2}{c}{ Type (Experimental condition) } & Piston skirt OD & Cold clearance & \multicolumn{2}{c}{ Skirt roughness } \\
& & $\mathrm{mm}$ & $\mu \mathrm{m}$ & $\mu \mathrm{m} \mathrm{Ra}$ \\
\hline Small piston & (motored condition) & 82.380 & 130 & - \\
Rough (standard) skirt piston & (fired condition) & 82.488 & 22 & 2.38 \\
Smooth skirt piston & (fired condition) & 82.486 & 24 & 0.54 \\
\hline
\end{tabular}

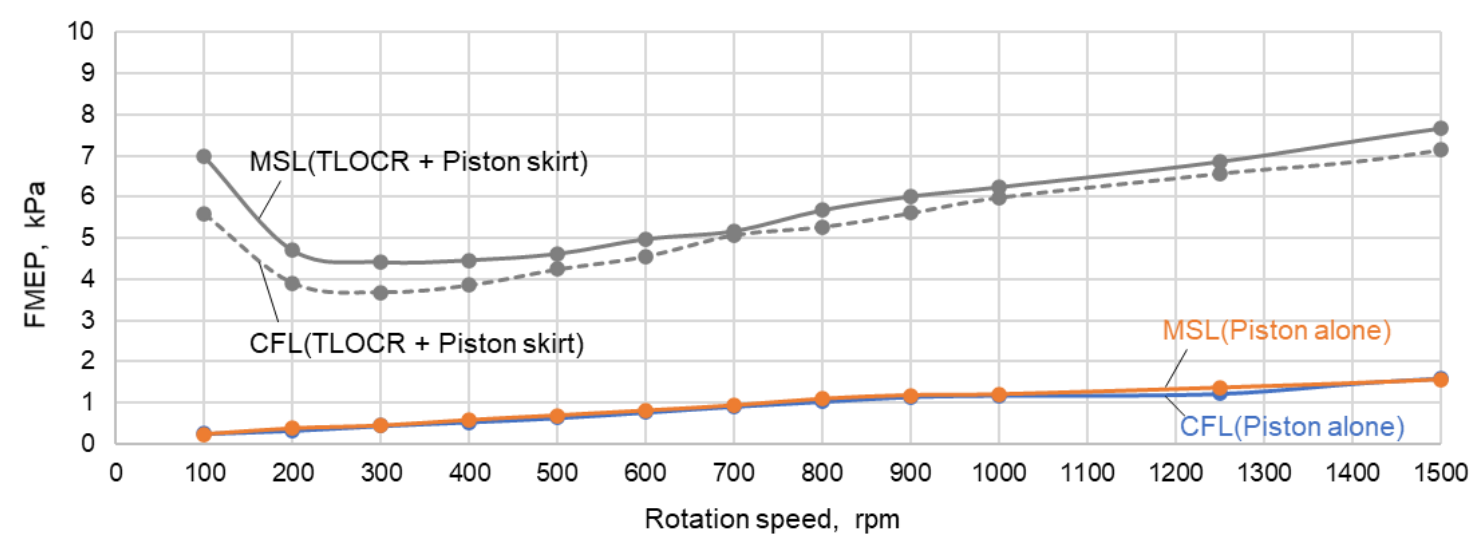

Fig. 3 Comparison of friction mean effective pressure (FMEP) between the MSL and the CFL with piston alone

Table 2 Specifications of the piston rings

\begin{tabular}{lcc}
\hline Type & Ring tension & Land width \\
& $\mathrm{N}$ & $\mu \mathrm{m}$ \\
\hline Top ring & 9.4 & - \\
Second ring & 10.3 & - \\
Oil control ring (TLOCR) & 19.5 & 85 \\
\hline
\end{tabular}

\subsection{Specifications of the floating liner engine}

Friction of piston rings and a piston skirt was measured by using a floating liner engine (FLE). Figure 4 shows the structure of the FLE. The cylinder liner of the FLE is separated from the cylinder block, and lateral stoppers support side force of the piston. There are two load pickups on the bottom of the device. These sensors convert the load received from the piston system into a voltage signal. Table 3 shows the specifications of the FLE. The bore of the FLE is $82.5 \mathrm{~mm}$, the stroke is $92.8 \mathrm{~mm}$, and the displacement is $0.496 \mathrm{~L}$. The compression ratio is 10 . 


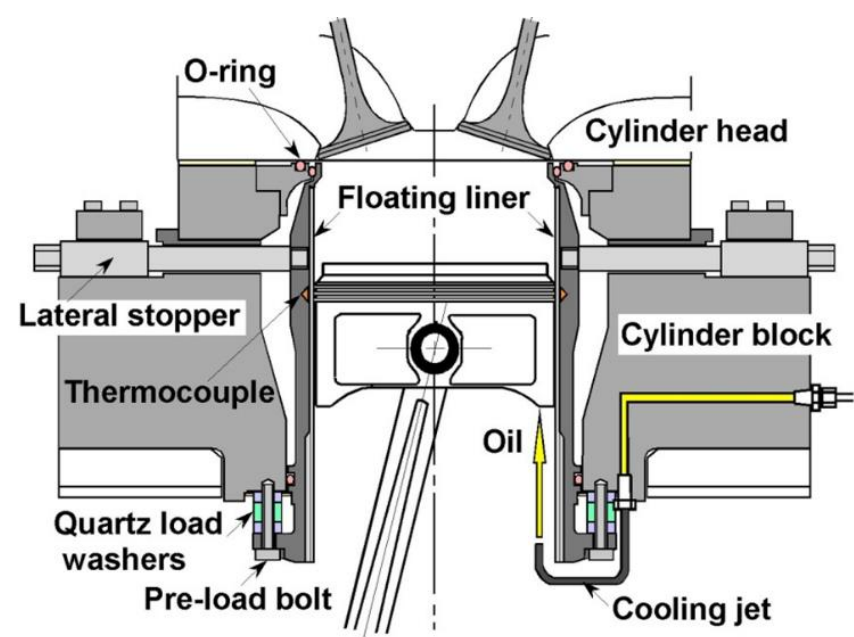

Fig. 4 Structure of the floating liner engine

Table 3 Specifications of the floating liner engine

\begin{tabular}{lc|c}
\hline Type & & Single cylinder four stroke gasoline engine \\
Bore & $\mathrm{mm}$ & 82.5 \\
Stroke & $\mathrm{mm}$ & 82.8 \\
Displacement & $\mathrm{L}$ & 0.496 \\
Compression ratio & & 10 \\
\hline
\end{tabular}

\section{Results and discussion}

\subsection{Lubrication condition of the TLOCR}

Figure 5(a) to (d) shows the comparisons of friction measurement result between the conventional fine-honed liner (CFL) and the microstructured liner (MSL) after 10 hours of break-in. Those experiments were conducted using large clearance piston with a twin-land oil control ring (TLOCR) alone under motored conditions at 100,300, 500 and $700 \mathrm{rpm}$.

The characteristic of the mixed lubrication is that the friction decreases as the piston speed increases. On the contrary, when the lubrication condition transitions to the hydrodynamic lubrication regime, the friction increases with the piston speed, and the friction in which the middle of the stroke shapes like a bow is shown. Further, when the lubrication condition of the ring is examined in cylinder liners which have different surface textures, in general, the larger the roughness, the larger the friction. However, despite the roughness difference, it may show a very close friction in the middle of the stroke. This is because the frequency of asperity contacts between the ring and the liner decreases due to the increase in the oil film, which is a sign of the transition to hydrodynamic lubrication. 


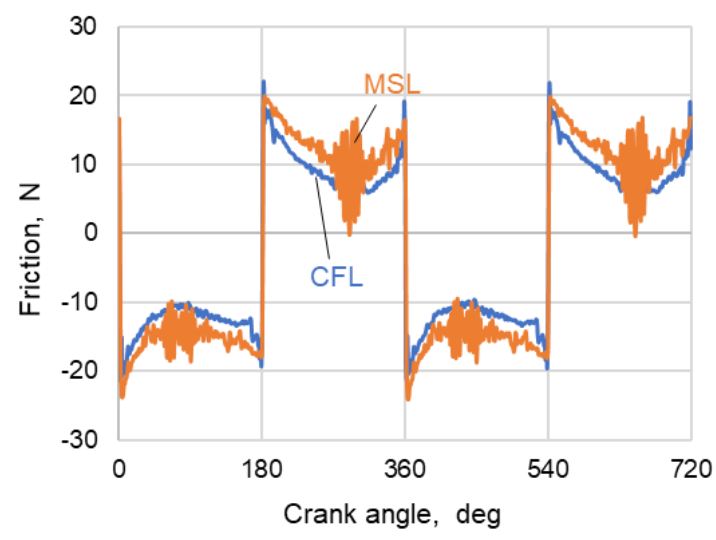

(a) $100 \mathrm{rpm}$

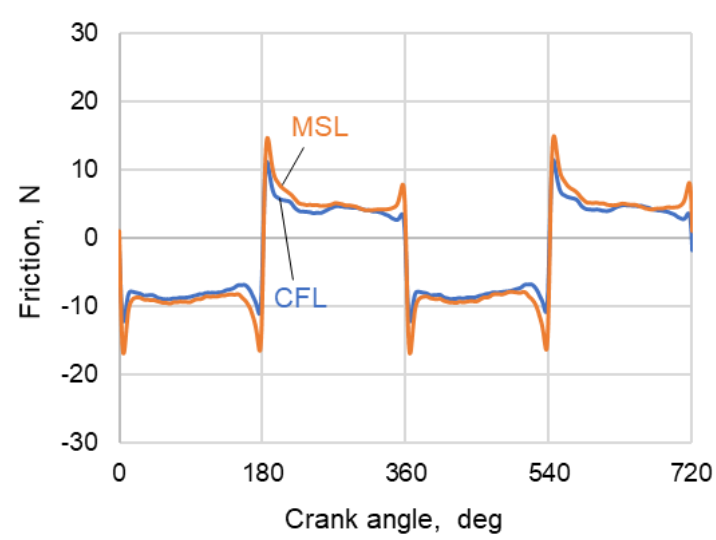

(c) $500 \mathrm{rpm}$

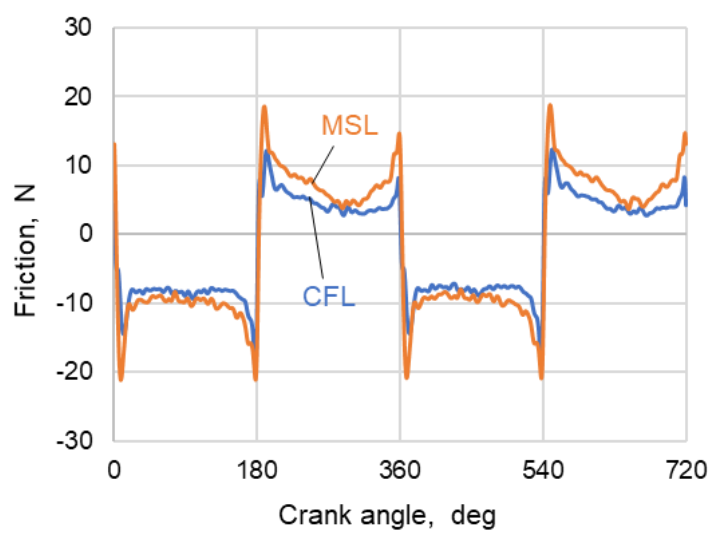

(b) $300 \mathrm{rpm}$

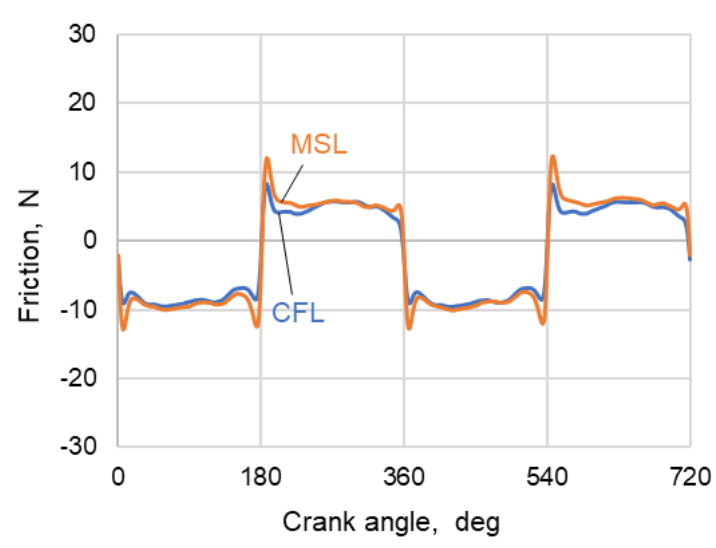

(d) $700 \mathrm{rpm}$

Fig. 5 Comparisons of friction measurement result between the conventional fine-honed liner (CFL) and the microstructured liner (MSL) after 10 hours of break-in ( Oil temp.: $80^{\circ} \mathrm{C}$, Cylinder temp.: $\left.80^{\circ} \mathrm{C}\right)$

Both the CFL and the MSL indicate the feature of the mixed lubrication at lower engine speed such as 100 and $300 \mathrm{rpm}$. However, the feature of the hydrodynamic lubrication becomes significant at higher speed such as 500 and $700 \mathrm{rpm}$. When the lubrication regime of the TLOCR transitions to the hydrodynamic lubrication due to an increase of the engine speed, the effect of asperity contact becomes relatively small, and the friction of CFL and MSL roughly matches. TLOCR runs under the hydrodynamic regime in only a limited area of mid-stroke at $300 \mathrm{rpm}$, while the lubrication regime at $700 \mathrm{rpm}$ is mainly the hydrodynamic regime except for the vicinity of both the top and the bottom dead center.

Figure 6(a) compares the friction among the CFL at $100 \mathrm{rpm}$, the MSL at $100 \mathrm{rpm}$ and the MSL at $200 \mathrm{rpm}$ in the intake stroke (0-180 degrees crank angle (deg CA)). The negative sign of friction simply indicates that the sliding direction is downward of the cylinder liner. Figure 6(b) shows the comparison of Stribeck curves in 120-160 deg CA using friction measurement results in Figure 6(a). The range of 120$160 \mathrm{deg}$ CA is suitable for comparison of lubrication conditions because stable experimental results can be 
obtained regardless of motored or fired conditions. Here, in order to make it easy to understand where the lubrication regime of each operating conditions of the interest is, the CFL of more than $200 \mathrm{rpm}$ are added by the outline circles in blue, and the MSL of more than $300 \mathrm{rpm}$ are added by the outline circles in orange.

In Figure 6(a), the friction of the MSL at $100 \mathrm{rpm}$ is always larger than the friction of the CFL at $100 \mathrm{rpm}$. It also indicates that the friction of CFL at $100 \mathrm{rpm}$ and the friction of MSL at $200 \mathrm{rpm}$ is equivalent to each other. From Figure 6(b), it turns out that the TLOCR runs under the mixed lubrication regime in average under these three operating conditions. In the mixed lubrication regime, the friction due to asperity contact is generally dominant over the hydrodynamic friction. Therefore, the contact condition of TLOCR with the liner appears strongly in the friction measurement result. Further, since the structure occupies $16 \%$ of the entire liner area in the MSL, if the oil film thickness is equivalent between the liners, namely if the contact condition is equivalent, the MSL is expected to improve friction compared to that of the CFL because of less sliding area. Nevertheless, the friction of the MSL at $100 \mathrm{rpm}$ has larger friction than the CFL at $100 \mathrm{rpm}$. This suggests that the MSL at $100 \mathrm{rpm}$ has a thinner oil film between the sliding surfaces than that of the CFL at $100 \mathrm{rpm}$. In other words, it can be said that the MSL thins the oil film of the TLOCR and does not help improve the lubrication condition of the TLOCR which has a flat and narrow sliding surface.

A large fluctuation is observed in the friction of the MSL at $100 \mathrm{rpm}$ in Figure 6(a). This fluctuation disappeared when the engine speed turned $200 \mathrm{rpm}$. It is assumed that the fluctuation is caused by something of liner surface structure. The MSL was made based on the CFL and the microstructure was machined in the final process. The roughness of the plateau part of the MSL and the CFL is the same, and the edge around the structure created due to the mechanical manufacturing is considered to be the reason of the fluctuation in friction. Since the fluctuation in fiction is seen only in the middle of the stroke, it is assumed that high edges remained around the structure of the relevant part during the processing. Usually, the edge wears during the break-in. However, it is considered that the height of the edge remains for a long time because the structure at the beginning is large compared to the roughness created by honing. It is assumed that the fluctuation in fiction occurred due to the oil ring being caught in this large undulation. 


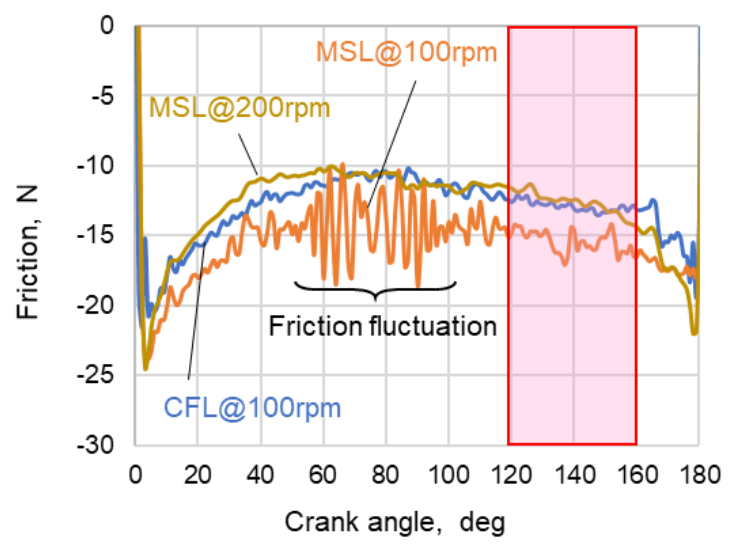

(a) Friction comparison (0-180 deg CA)

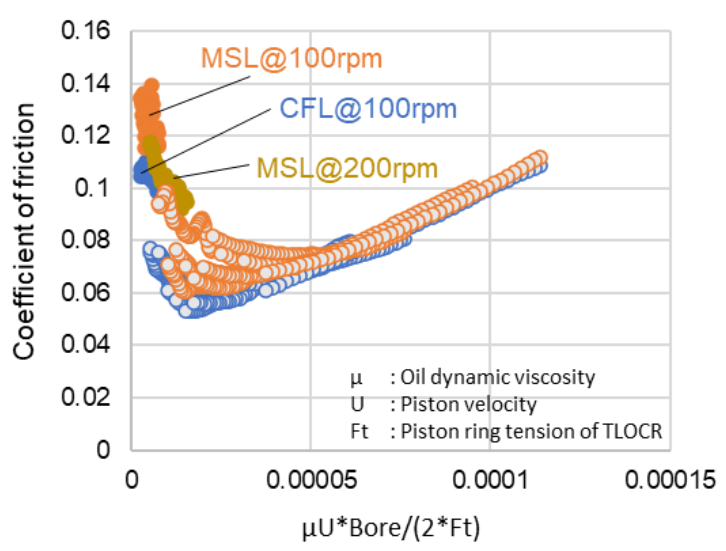

(b) Comparison of Stribeck curves

Fig. 6 Comparisons of the lubrication conditions among the MSL at $100 \mathrm{rpm}$, at $200 \mathrm{rpm}$, and the CFL at 100 rpm (Oil temp.: $80^{\circ} \mathrm{C}$, Cylinder temp.: $8^{\circ} \mathrm{C}$ )

Next, cylinder liners were operated under fired conditions for several tens of hours and then friction measurements under motored condition with TLOCR alone were performed again. These extended break-in operations were continued until the friction mean effective pressure (FMEP) gave a stable result. The CFL was operated for 35 hours and the MSL was operated for 50 hours. Figure 7 shows the friction measurement results of the TLOCR after the extended breaking-in. At first, the fluctuation in friction in the MSL at $100 \mathrm{rpm}$ has disappeared. At $100 \mathrm{rpm}$, it still shows the characteristics of mixed lubrication. However, the difference in friction between the MSL and the CFL became small. At 300 rpm, the characteristics of the hydrodynamic lubrication are now clearly visible. This becomes more obvious as the rotation speed increases. Due to the long-term operation, the edges around the microstructure are sufficiently worn, and the effect on the friction measurement is considered to be negligible. The difference in frictional force between the MSL and the CFL is clearly smaller than at 10 hours. However, the MSL is still always slightly larger. Differences are observed mainly in the vicinity of the top dead center (TDC) and the bottom dead center (BDC).

Figure 8 is a plot of FMEP over the rotation speed, which helps understand the overall change in lubrication condition. After sufficient break-in time, it was observed that FMEP of the MSL was always larger than that of the CFL. On the other hand, in the friction trace at high rotation speed, the friction in the mid stroke is almost the same. From the above, it is explained that the difference in FMEP comes mainly from the difference in friction in the mixed lubrication regime namely in the vicinity of the TDC and the BDC. 


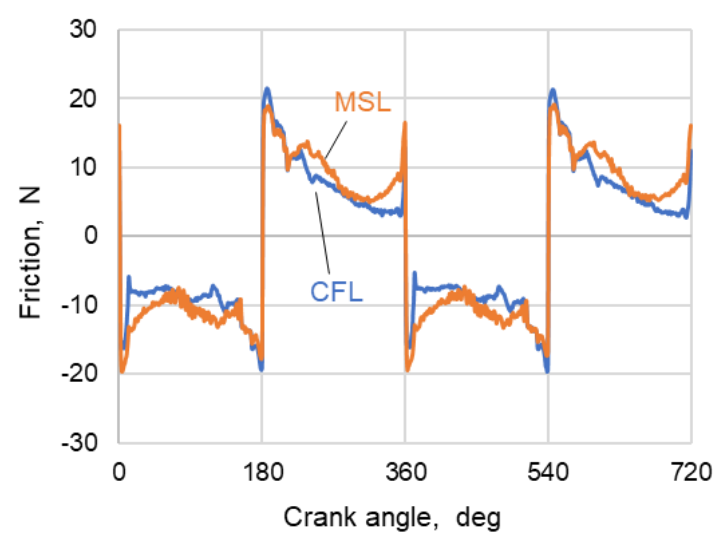

(a) $100 \mathrm{rpm}$

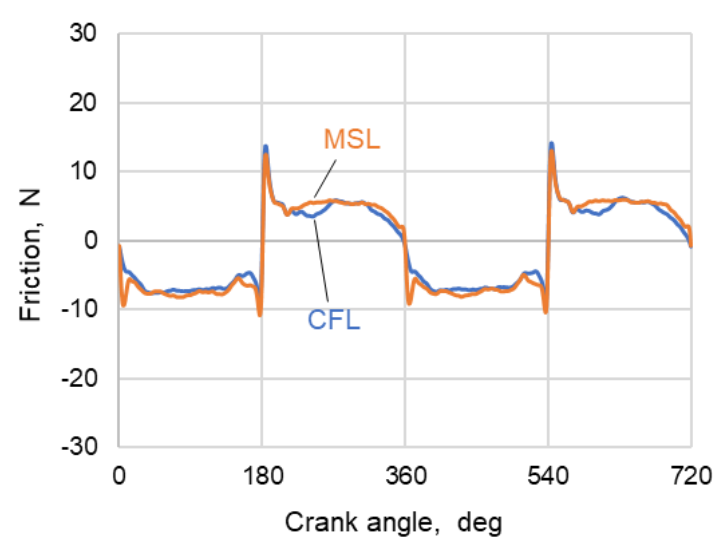

(c) $500 \mathrm{rpm}$

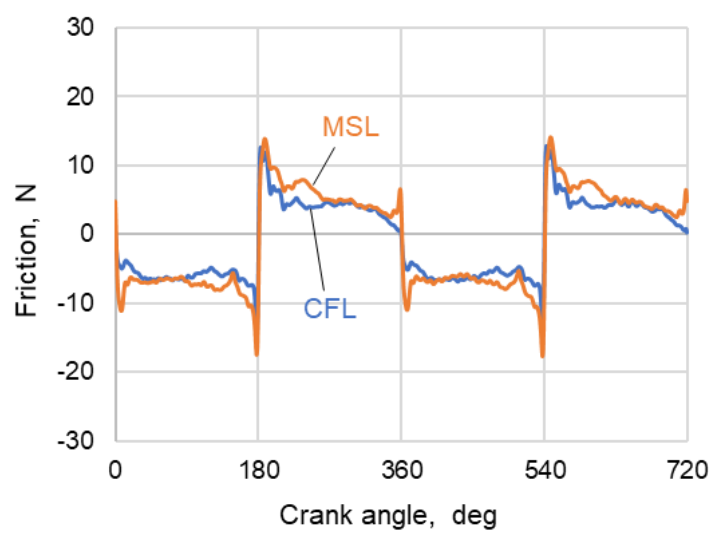

(b) $300 \mathrm{rpm}$

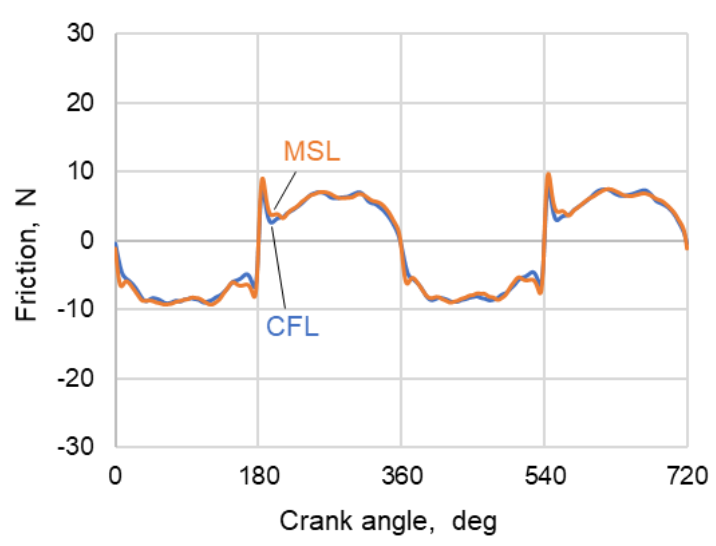

(d) $700 \mathrm{rpm}$

Fig. 7 Comparison of friction measurement results between the conventional fine-honed liner (CFL) and the microstructured liner (MSL) after the extended breaking-in (Oil temp.: $80^{\circ} \mathrm{C}, \mathrm{Cylinder}$ temp.: $\left.80^{\circ} \mathrm{C}\right)$

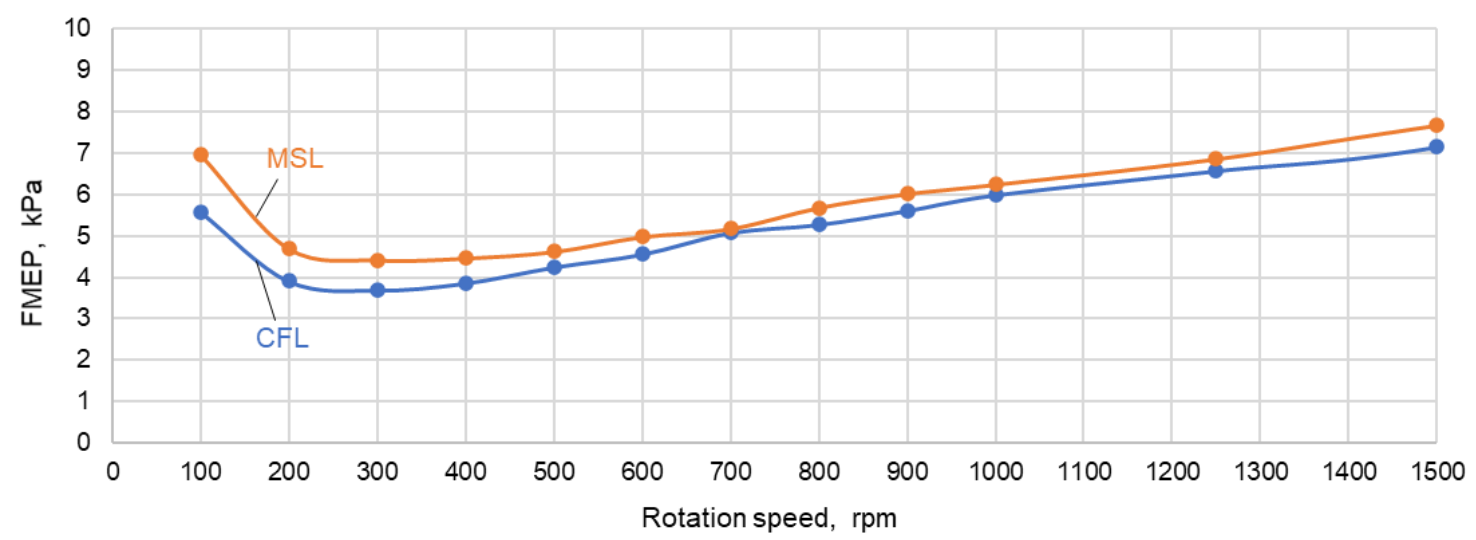

Fig. 8 Variation of FMEP over engine rotation speed for the microstructured liner and the conventional fine-honed liner (Oil temp.: $80^{\circ} \mathrm{C}$, Cylinder temp.: $80^{\circ} \mathrm{C}$ ) 
The reduction of the sliding area normally improves the load capacity of the sliding surface and improves lubrication condition. However, as for the TLOCR, the reduction of the sliding area using surface texturing can mean the loss of the source of pressure generation. This is because dynamic pressure is generated only by small wedge shapes consisting of liner surface roughness and the sliding surface of the TLOCR [6]. This is also because the micro-hydrodynamic effect of the texturing cannot be expected since the sliding surfaces of the TLOCR are flat. Therefore, the sum of the pressure generation in the plateau part of the MSL is considered not to reach the sum of the CFL's, resulting in a thinner oil film thickness. Although the interaction between the liner roughness and the sliding surface of the TLOCR should become larger when the oil film thickness gets thin, and is considered insufficient to lift the TLOCR up at low piston speed range. Therefore, the MSL leads an increase of the asperity contact with the TLOCR in the vicinity of the TDC and the BDC as a result.

Here, oil film parameter $\Lambda$ in the mixed lubrication regime is defined as $1<\Lambda<3$ in the equation (1).

$$
\Lambda=\frac{h_{\min }}{\sqrt{\sigma_{\text {liner }}^{2}+\sigma_{\text {ring }}^{2}}}
$$

Where $h_{\min }$ is the minimum oil film thickness, $\sigma_{\text {liner }}$ is the root mean square (RMS) roughness of the plateau part of the liner, and $\sigma_{\text {ring }}$ is the RMS roughness of the TLOCR. Further, since the contact width of the TLOCR is small, it is assumed that $h_{\text {mean }} \fallingdotseq h_{\text {min }}$. Here, $h_{\text {mean }}$ is the mean oil film thickness of the TLOCR. Since the TLOCR has been used for a sufficiently long time and its surface roughness is extremely small, ignoring ring running surface roughness $\left(\sigma_{\text {ring }}=0\right), \Lambda$ can be assumed to the ratio of the oil film thickness to the RMS roughness of the liner. Here, in the case of the MSL and the CFL used in the experiment, $\sigma_{\text {liner }}$ is approximately $0.2 \mu \mathrm{m}$. As a result, the range of oil film thickness of the TLOCR in the mixed lubrication condition is estimated to be $0.2<h_{\text {mean }}<0.6 \mu \mathrm{m}$. In addition, even in the hydrodynamic lubrication regime, the oil film thickness is not likely to exceed the roughness level significantly. When the sliding surface of the piston ring has a parabolic profile like a general three-piece oil control ring (TPOCR) for example, it is possible to form a large wedge with the liner surface, thereby to generate a dynamic pressure. However, it is difficult for a TLOCR to generate dynamic pressure. Again, this is because dynamic pressure is generated only by small wedge shapes consisting of liner surface roughness in the case of the TLOCR which has flat sliding surfaces. Namely, if the oil film is too thick, the interaction cannot be obtained. This fact also means that the friction of the TLOCR can deteriorate by a slight loss of the pressure generation even when the TLOCR runs in the hydrodynamic regime. The question is why the lubrication condition of the TLOCR with the MSL in the hydrodynamic lubrication regime does not deteriorate. If the oil film thickness of the TLOCR with the MSL become thin because of the lack of the effective area, the interaction between the TLOCR and the liner roughness will increase at the same time when the piston speed is high. Eventually, there may be almost no difference in oil film thickness between the MSL and the CFL. 
Regarding sliding parts that runs under the hydrodynamic lubrication regime, it has been reported that liner dimple texturing reduces hydrodynamic friction [10]. However, from the friction measurement results in this study, no clear advantage of the MSL with the TLOCR was observed even in the high piston speed region. As mentioned earlier, there is a chance that the dimple shaped surface structures do not work for sliding parts which runs under mixed lubrication regime. On the other hand, the edges created in the machining process could be large and remain on the surface semi-permanently. Therefore, it still is suspicious that the edges could contribute to the increase of friction even in the hydrodynamic-dominant lubrication regime. With respect to this point, further research is needed.

\subsection{Lubrication condition of a piston skirt}

Figure 9 shows the comparison of the FMEP between the MSL and the CFL under fired conditions. The results indicate overall decreased friction losses of the MSL compared to the CFL. The improvement of the FMEP became more remarkable at higher engine speed and lower load. The improvement reached $9.1 \%$ at $2000 \mathrm{rpm}$ and 4 bar indicated mean effective pressure (IMEP) condition. On the contrary, at $1000 \mathrm{rpm}$ and 8 bar IMEP, which represents the most severe lubrication condition to the sliding parts within these experiments, the FMEP of the MSL became slightly worse. Figure 10 shows the comparison of friction traces between the MSL and the CFL. It can be seen that the friction trace of the MSL shows an improvement in friction in the middle of the stroke and it becomes more remarkable at higher speed and lower load. The friction traces have a feature of the hydrodynamic lubrication in the middle of the stroke. Therefore, the improvement of the FMEP is deemed to mainly come from the improvement in hydrodynamic friction. Thus, it is more likely that the improvement come from the sliding parts that have a parabolic sliding surface and can generate dynamic pressure in the sliding area such as piston (skirt) and piston top ring. The MSL has $16 \%$ less sliding area than the CFL because of the microstructure, and the reduction of the sliding area reduces friction effectively in the hydrodynamic lubrication regime. Namely, the improvement of the friction is considered to be an effect of the microstructure. In addition, when using the MSL, it is assumed that oil is dragged out from the microstructure to the plateau by the piston rings. This additional oil may help to build oil film and improve the lubrication condition. 


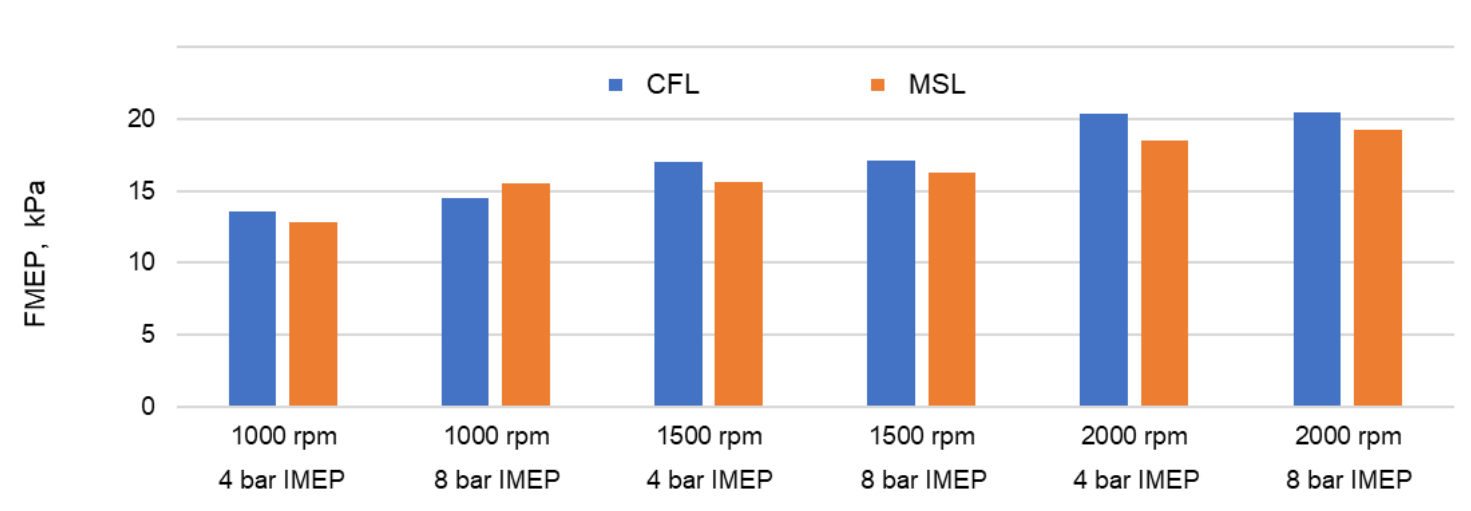

Fig. 9 Comparison of the friction mean effective pressure (FMEP) between the microstructured liner (MSL) and the conventional fine-honed liner (CFL) under fired conditions (Oil temp.: $\mathbf{8 5}^{\circ} \mathrm{C}$, Cylinder temp.: $\left.\mathbf{1 0 0}^{\circ} \mathrm{C}\right)$ 


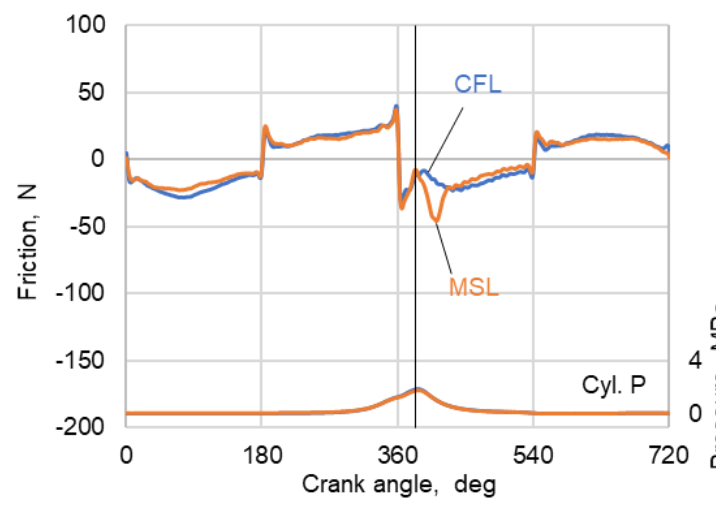

(a) $1000 \mathrm{rpm}, 4$ bar IMEP

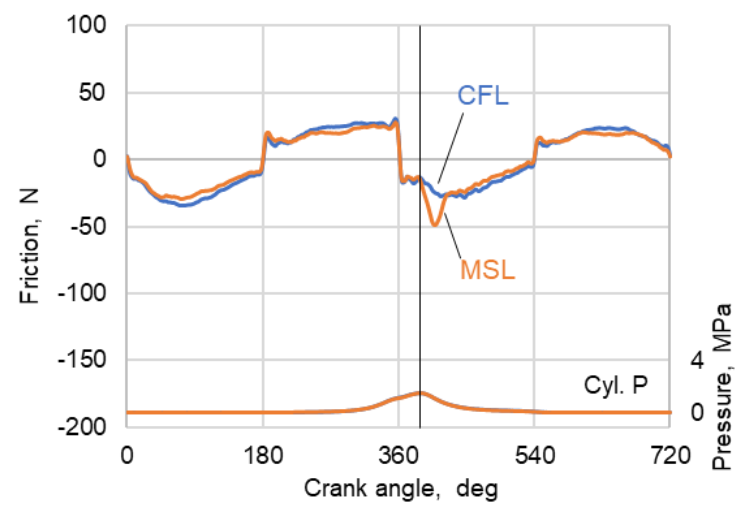

(c) $1500 \mathrm{rpm}, 4$ bar IMEP

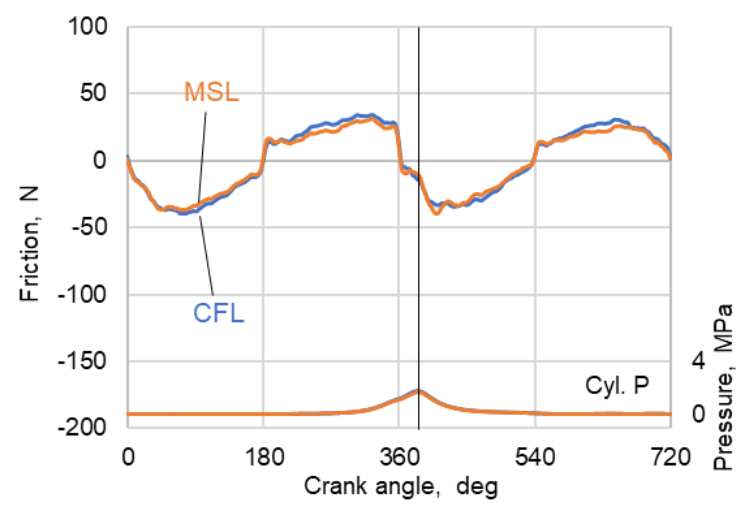

(e) $2000 \mathrm{rpm}, 4$ bar IMEP

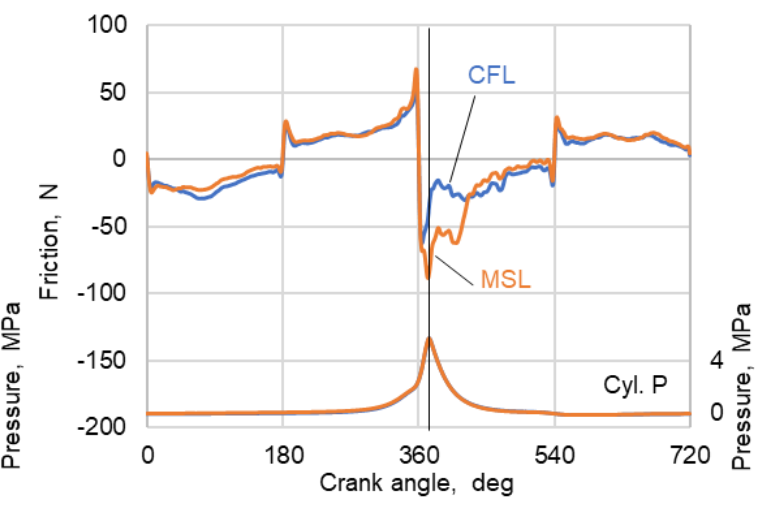

(b) $1000 \mathrm{rpm}, 8$ bar IMEP

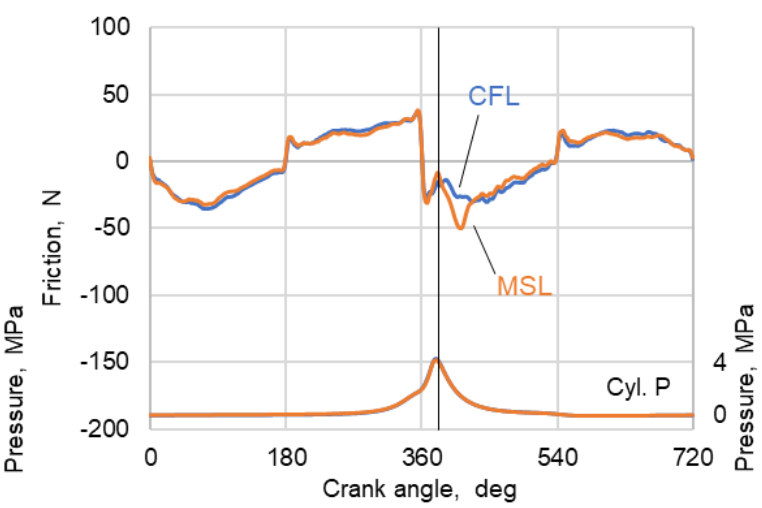

(d) $1500 \mathrm{rpm}, 8$ bar IMEP

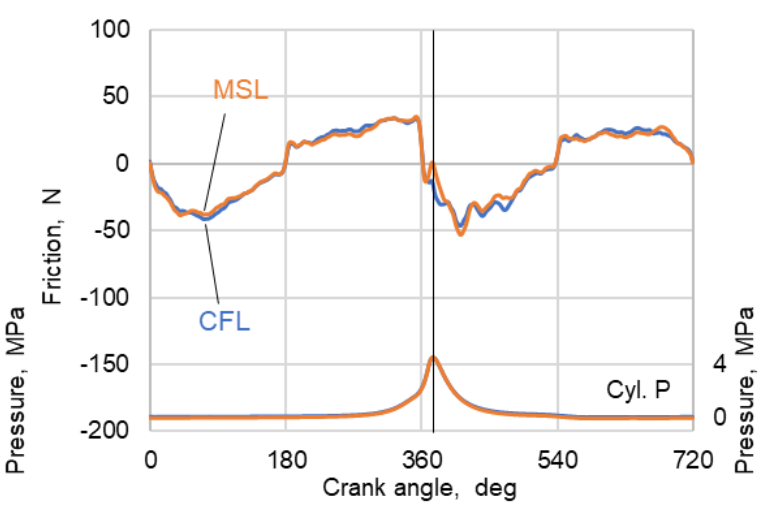

(f) $2000 \mathrm{rpm}, 8$ bar IMEP

Fig. 10 Comparison of the friction measurements between the microstructured liner (MSL) and the conventional fine-honed liner (CFL) under fired conditions (Oil temp.: $8^{\circ} \mathrm{C}, \mathrm{Cylinder}$ temp.: $\mathbf{1 0 0}^{\circ} \mathrm{C}$ )

On the other hand, the deterioration of the friction was observed in early expansion stroke. One is around 50 degrees after the TDC, and another is in the vicinity of the peak of the cylinder pressure. The former is when the side force acting on the piston becomes the highest. Here, the microstructures on the surface of the MSL have a long shape in the circumferential direction, as sketched in Figure 11. When the piston skirt approaches the cylinder liner after the top dead center, oil can escape easily in the circumferential direction. Therefore, it is difficult to use the squeeze effect. It is considered that this causes 
oil starvation in the region where the piston side force is large and leads a deterioration of the friction of piston skirt. The latter is the timing when the lubrication condition of the top ring becomes severe because of the cylinder pressure acting as back-pressure. However, this is observed only at $1000 \mathrm{rpm}$ and 8 bar IMEP condition, if anything, the friction of the MSL is smaller than the CFL at the focused timing under other operating conditions. As we will see later, this phenomenon is not only due to the top ring, but also to the combination of the top ring and piston skirt. The top ring has parabolic shape on the sliding surface and can generate dynamic pressure in lubricating oil. However, it is deemed that the less sliding area of the MSL has a negative effect when the back-pressure exceeds the capacity of dynamic pressure generation under low speed and high load condition. As for the piston skirt, piston moves quickly from anti-thrust side to thrust side in the cylinder liner. At that time, as mentioned above, it is difficult for the microstructure adopted this time to hold enough oil on the sliding surface. As a result, friction of the piston skirt is considered to deteriorate as well.

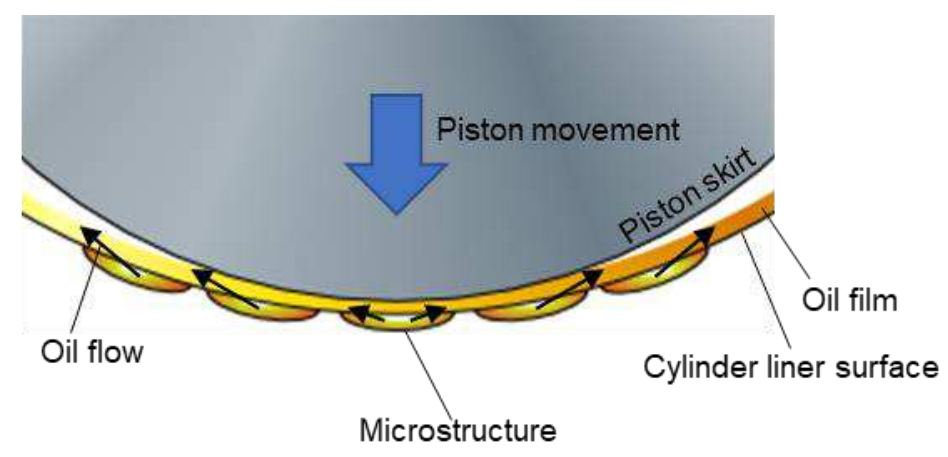

Fig. 11 Oil behavior in microstructure during piston slap

On the one hand, a piston generally has machine marks which looks like streaky grooves in the circumferential direction. These machine marks are considered to improve lubrication condition by holding oil and hiding particles. On the other hand, it is also known that reducing the roughness of the piston skirt decreases the friction loss. Takiguchi measured the piston friction and investigated wear of the piston skirt by using two pistons which have different piston skirt roughness (One had $2.05 \mu \mathrm{m} \mathrm{Ra}$, another had 0.65 $\mu \mathrm{m} \mathrm{Ra)} \mathrm{[13].} \mathrm{As} \mathrm{a} \mathrm{result,} \mathrm{he} \mathrm{explained} \mathrm{that} \mathrm{there} \mathrm{is} \mathrm{a} \mathrm{friction} \mathrm{improvement} \mathrm{effect} \mathrm{in} \mathrm{the} \mathrm{reduction} \mathrm{of} \mathrm{piston}$ skirt roughness. This is because reducing roughness reduces metal contacts. Here, the microstructure on the liner has a depth of $7 \mathrm{um}$. On the other hand, the roughness of the piston skirt is $2.38 \mu \mathrm{m} \mathrm{Ra}(9.46 \mathrm{Rz})$. The dimension of height of the structure is comparable. Now the question is that the friction feature using the MSL comes from whether the liner microstructure alone or the combination of the MSL and the piston skirt roughness. To compare the magnitude of the effect on friction loss between the microstructure and the piston skirt roughness, first, friction measurements with different skirt roughness pistons were performed using the CFL. Whereas the piston skirt discussed so far has general machine marks (henceforth rough 
skirt/piston), the piston used for confirmation has no machine marks and has a smooth skirt with $0.54 \mu \mathrm{m}$ $\mathrm{Ra}$ (hereafter smooth skirt/piston). Both have the same skirt profile. As for the diameter of pistons, the diameter of the rough piston is $82.488 \mathrm{~mm}$ and the smooth piston is $82.486 \mathrm{~mm}$ during cold condition. The difference of 2 um is considered to be small enough compared to the translational movement distance of the piston after combustion TDC. Figure 12 compares the cycle friction trace of the CFL with rough skirt and the CFL with smooth skirt. Figure 13 is a comparison of FMEP. From two figures, it was found that the smooth skirt piston reduces friction loss against the rough skirt, but it was not a large improvement compared to the effect of the MSL. The average oil film thickness formed by the squeeze effect when the piston approaches the cylinder liner right after the TDC is assumed to be the same for both rough and smooth skirts. Therefore, the improvement in friction is because smooth skirt reduces asperity contacts than rough skirt. 


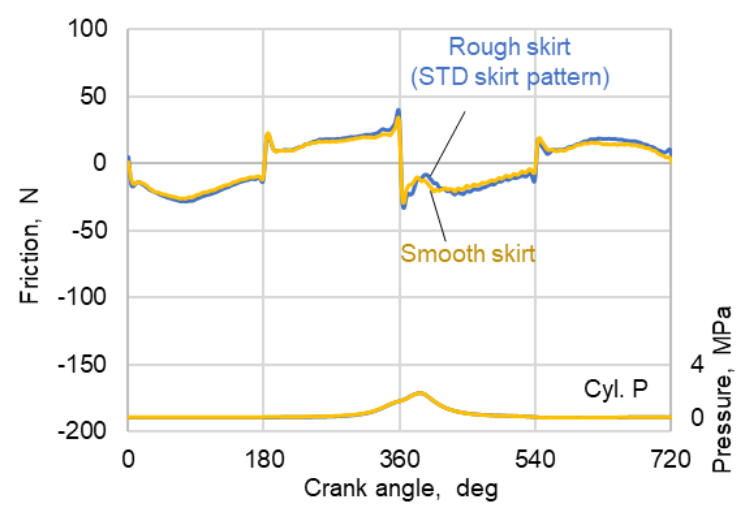

(a) $1000 \mathrm{rpm}, 4$ bar IMEP

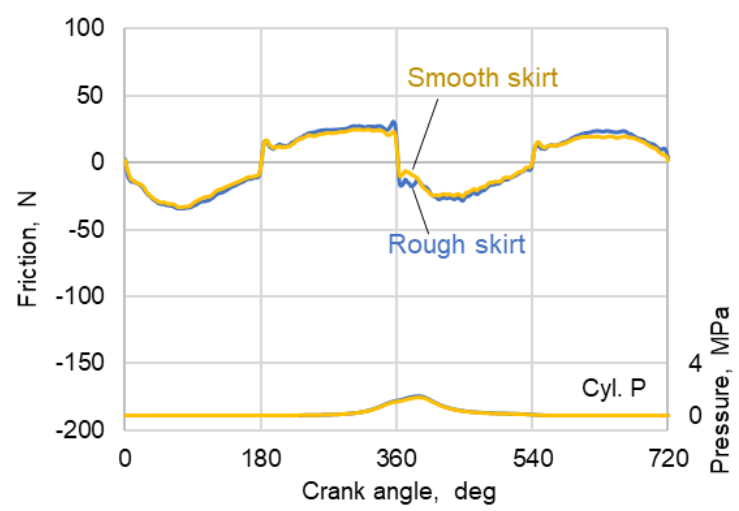

(c) $1500 \mathrm{rpm}, 4$ bar IMEP

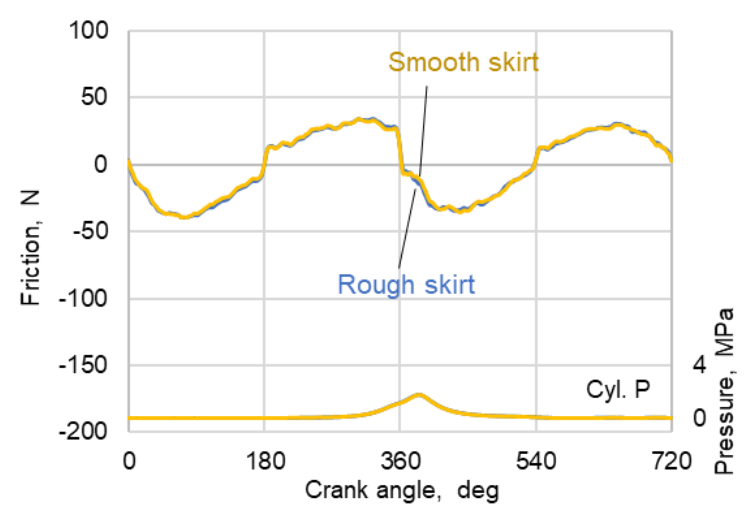

(e) 2000 rpm, 4 bar IMEP

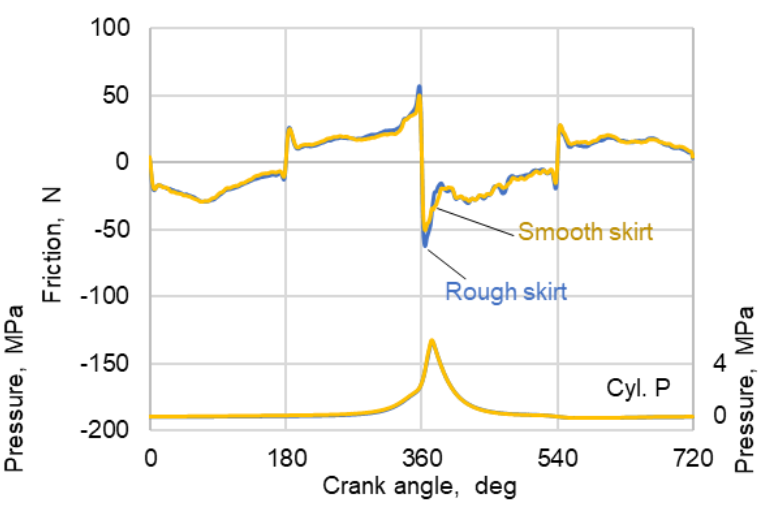

(b) $1000 \mathrm{rpm}, 8$ bar IMEP

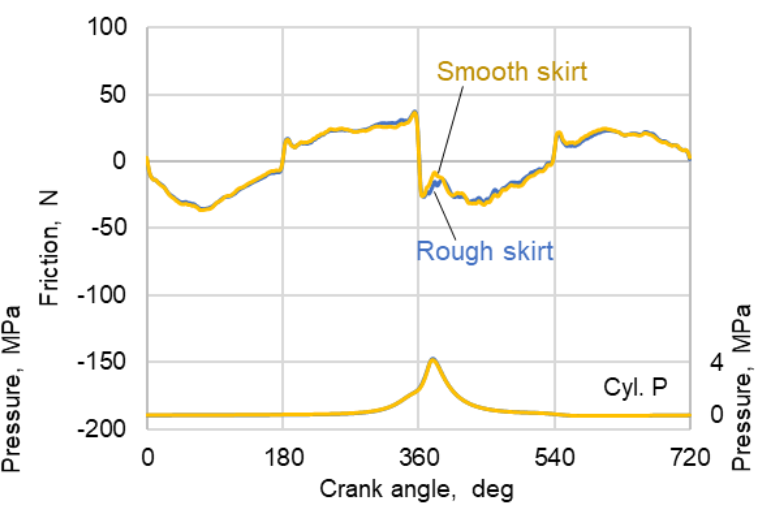

(d) $1500 \mathrm{rpm}, 8$ bar IMEP

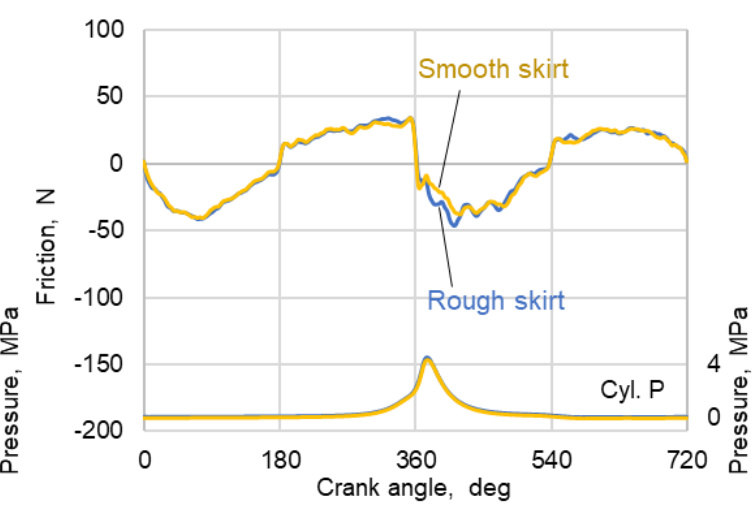

(f) $2000 \mathrm{rpm}, 8$ bar IMEP

Fig. 12 Comparison of the cycle friction trace between the CFL with rough skirt and the CFL with smooth skirt (Oil temp.: $8^{\circ} \mathrm{C}$, Cylinder temp.: ${ }^{100}{ }^{\circ} \mathrm{C}$ ) 


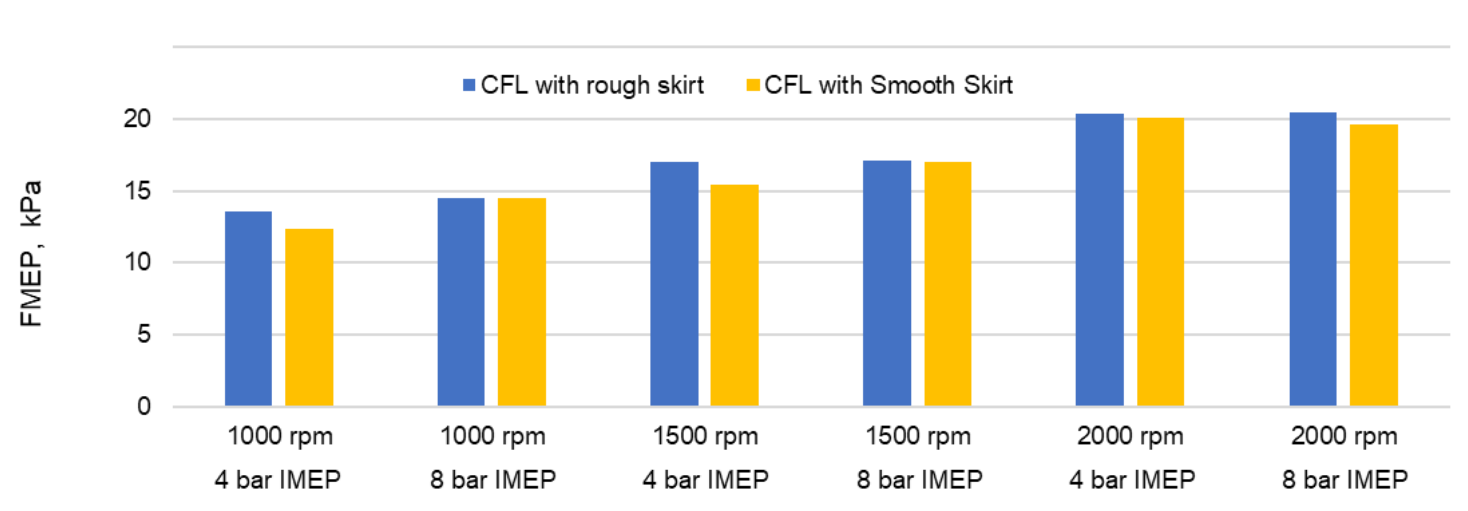

Fig. 13 Comparison of FMEP between the CFL with rough skirt and the CFL with smooth skirt (Oil temp.: $85^{\circ} \mathrm{C}$, Cylinder temp.: ${ }^{100}{ }^{\circ} \mathrm{C}$ )

Figure 14 compares the cycle friction between the MSL with rough skirt and the MSL with smooth skirt. Figure 15 shows the difference in FMEP. Contrary to the case of using the CFL, friction slightly deteriorated at almost all the experimental conditions with the smooth skirt. This deterioration of friction is particularly remarkable in the early expansion stroke at $1000 \mathrm{rpm}$ and 8 bar IMEP condition where the oil film generation is difficult. When the oil film between the cylinder liner and the piston skirt becomes thin in this area, the rough skirt may be able to store oil in the groove of the machine marks. On the other hand, it is difficult for the smooth skirt to store oil, and it may lead oil starvation. Initially, the friction deterioration at peak cylinder pressure was considered to come from the lubrication deterioration of the top ring. However, both experiments were performed using the same top ring, it was found that this phenomenon is based on the combination of the top ring and piston skirt. From the above examination, it was confirmed that the influence of the microstructure on the friction is much larger than the influence of the piston skirt roughness. Above results are considered to be greatly affected by the shape of the structure adopted to the cylinder liner this time, and it is worth considering the possibility of the microstructure shape and size that do not spoil squeeze effect. 


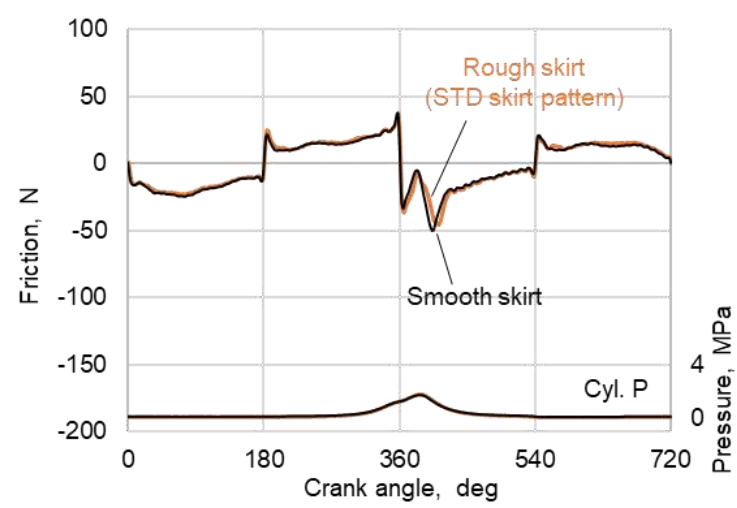

(a) $1000 \mathrm{rpm}, 4$ bar IMEP

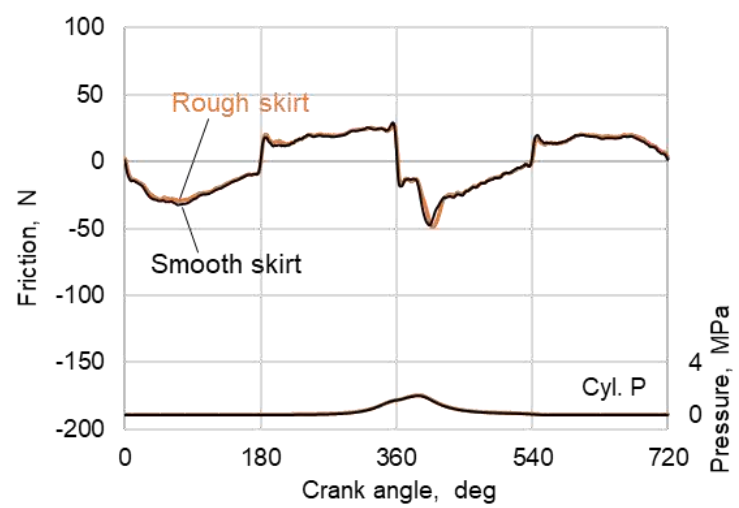

(c) $1500 \mathrm{rpm}, 4$ bar IMEP

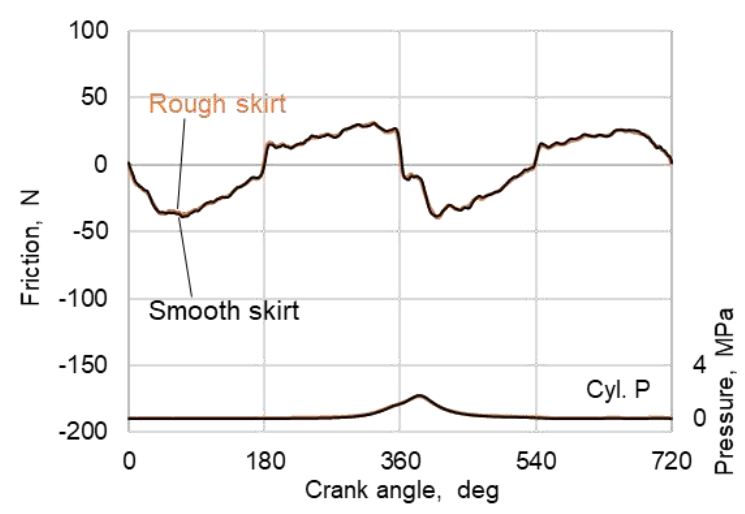

(e) $2000 \mathrm{rpm}, 4$ bar IMEP

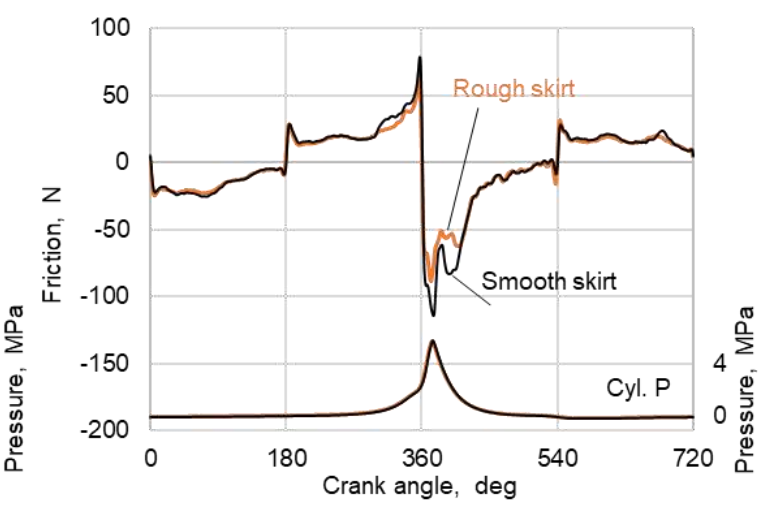

(b) $1000 \mathrm{rpm}, 8$ bar IMEP

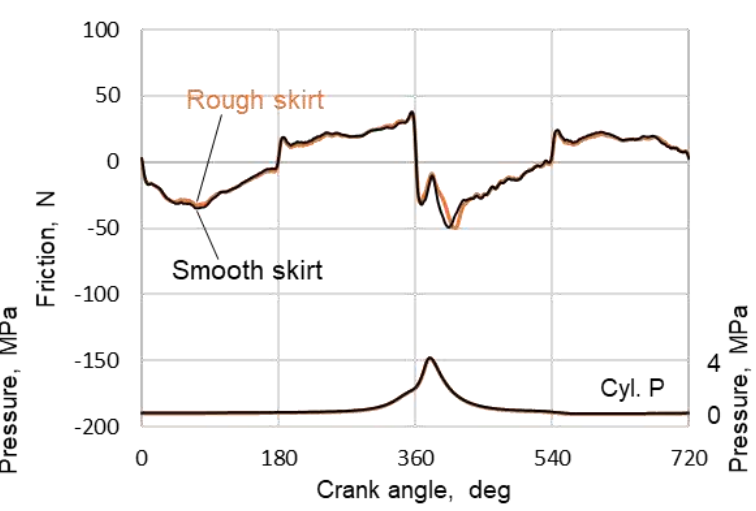

(d) $1500 \mathrm{rpm}, 8$ bar IMEP

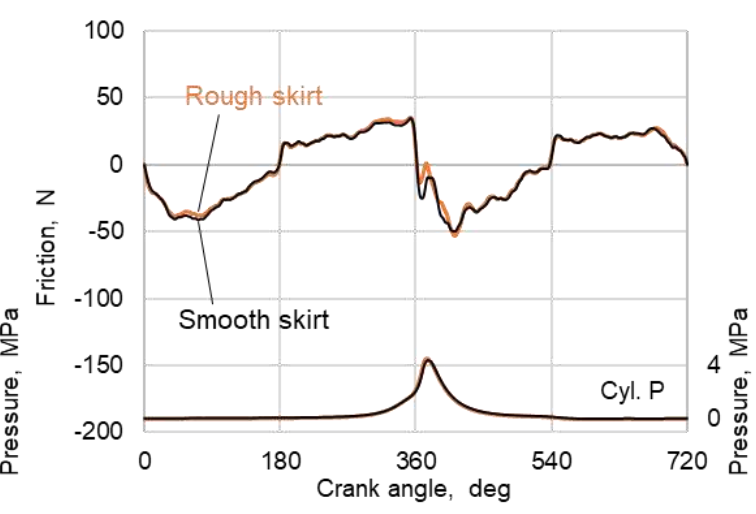

(f) $2000 \mathrm{rpm}, 8$ bar IMEP

Fig. 14 Comparison of the cycle friction trace between the MSL with rough skirt and the MSL with smooth skirt (Oil temp.: $8^{\circ} \mathrm{C}$, Cylinder temp.: $\mathbf{1 0 0}^{\circ} \mathrm{C}$ ) 


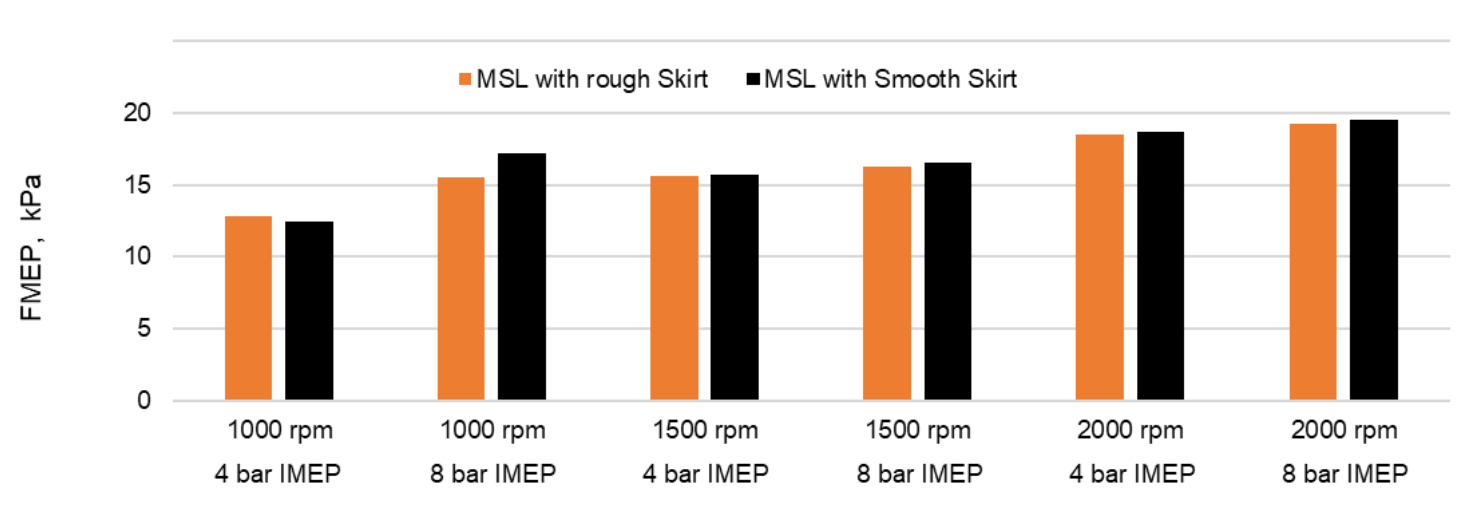

Fig. 15 Comparison of FMEP between the MSL with rough skirt and the MSL with smooth skirt (Oil temp.: $85^{\circ} \mathrm{C}$, Cylinder temp.: ${ }^{100}{ }^{\circ} \mathrm{C}$ )

Finally, microstructures are said to have the function of storing oil and redistributing it on the sliding surface. In this experiment, it was expected to improve the friction spike at the compression top dead center and at peak cylinder pressure timing where the lubrication of the top ring is severe. As shown in Figure 10, no significant change in the friction spike at the compression top dead center could be confirmed at all experiment conditions. On the other hand, focusing on the friction at peak cylinder pressure where is severe for the top ring to build oil film, we can see that the friction of the MSL is slightly improved except for the condition of $1000 \mathrm{rpm}$ and 8 bar IMEP. This was assumed to be an effect of oil redistribution by microstructure. Similar to TLOCR lubrication, the friction deterioration under the condition of $1000 \mathrm{rpm}$ and 8 bar IMEP is assumed that the MSL contributed to the occurrence of direct contact between the cylinder liner and the top ring in the mixed lubrication regime. However, further study is required for the detail.

\section{Conclusion}

Knowledge of lubrication function of surface structures such as dimples and pores is yet to be completed. In an internal combustion engine, some parts run mainly under hydrodynamic lubrication regime, and others run mainly under mixed lubrication regime. Knowing how microstructures affect sliding parts in different lubrication regime will help designing machineries. In this study, effects of microstructure laid on the cylinder liner surface of an engine on twin-land oil control ring (TLOCR) and piston lubrication have been investigated. In conclusion, following results have been achieved:

1. Lubrication condition of the TLOCR with the microstructured liner (MSL) deteriorated at low rotation speed and high load condition, and no significant improvement effect was observed at high speed. The reduction of the sliding area is considered to act as the loss of the source of pressure generation for the lubrication of TLOCR. Depending on the conditions, there is a chance that the dimple shaped surface structures do not work for sliding parts which runs under mixed lubrication regime.

2. The reason of no significant improvement in TLOCR's lubrication at high-speed region could be from 
the edges of the microstructure. Namely, the edges of the microstructure could contribute to the increase of FMEP even in the hydrodynamic-dominant lubrication regime. Therefore, when machining the microstructure, care is needed to ensure removal of hard elevated edges.

3. The MSL improved whole piston system lubrication condition in the hydrodynamic lubrication regime. The main reason is considered that the microstructure has an effect to reduce hydrodynamic friction of sliding parts which runs under the hydrodynamic lubrication regime such as the piston by the reduction of the sliding area. Oil dragged out from microstructure and redistributed on the sliding surface is also considered to help improving lubrication conditions.

4. The liner microstructure deteriorated lubrication condition of the piston skirt in the region where the piston side force is large. The tested microstructure has a shape that let oil go easily from the sliding surface and that may lead the oil starvation. Therefore, effects of different microstructure shape are a matter for future investigation.

5. It was also found that the effect of the liner microstructure on piston friction is larger than the effect of piston skirt roughness.

\section{Acknowledgments}

This work was sponsored by Daimler and the Consortium on Lubrication in Internal Combustion Engines in the Sloan Automotive Laboratory, Massachusetts Institute of Technology. The consortium members were Mahle, Rolls-Royce Solutions, Shell, Toyota, Volkswagen, Volvo Trucks, and Weichai Power. Authors deeply thank members for the corporation.

\section{References}

[1] Heywood, J. B.: Internal Combustion Engine Fundamentals, pp.725-730, McGraw-Hill Book Company(1988)

[2] Tian T.: Dynamic behaviours of piston rings and their practical impact. Part 1: Ring flutter and ring collapse and their effects on gas flow and oil transport, Proc. IMechE, Part J: J Engineering Tribology, Vol. 216, Issue 4, pp. 209-228(2002), https://doi.org/10.1243\%2F135065002760199961

[3] Tian T.: Dynamic behaviours of piston rings and their practical impact. Part 2: Oil transport, friction and wear of ring/liner interface and the effects of piston and ring dynamics, Proc. IMechE, Part J: J Engineering Tribology, Vol. 216, Issue 4, pp. 229-248(2002), https://doi.org/10.1243\%2F135065002760199970

[4] Liu, Y., Li, Y., and Tian, T.: Development and Application of Ring-Pack Model Integrating Global and Local Processes. Part 2: Ring-Liner Lubrication, SAE Int. J. Engines, Vol. 10, Issue 4, pp. 1969-1983(2017), https://doi.org/10.4271/2017-01-1047

[5] Richardson, D.E.: Review of power cylinder friction for diesel engines, ASME J. Eng. Gas Turbines Power, Vol. 122, Issue 4, pp. 506-519(2000), https://doi.org/10.1115/1.1290592 
[6] Li, Y., Chen, H., and Tian, T.: A Deterministic Model for Lubricant Transport within Complex Geometry under Sliding Contact and its Application in the Interaction between the Oil Control Ring and Rough Liner in Internal Combustion Engines, SAE Technical Paper 2008-01-1615(2008), https://doi.org/10.4271/200801-1615

[7] Liu, Y., Kim, K., Westerfield, Z., Meng, Z., and Tian, T.: A comprehensive study of the effects of honing patterns on twin-land oil control rings friction using both a numerical model and a floating liner engine, Proc. IMechE, Part J: Journal of Engineering Tribology, Vol. 233, Issue 2, pp. 299-255(2018), https://doi.org/10.1177\%2F1350650118774395

[8] Lu, P., Wood, R.J.K.: Tribological performance of surface texturing in mechanical applications-a review, Surface Topography: Metrology and Properties, Vol. 8, No. 4, 043001(2020)

[9] Yamasaka, K., Okamoto, D., Ito, A., Tahara, H., and Sumiyoshi, T., Effect of Texturing for Sliding Surface of a Piston Ring by Means of Ultrashort Pulse Laser on Friction Reduction, Trans. JSAE, Vol. 48, No. 2, pp. 271-276(2017), https://doi.org/10.11351/jsaeronbun.48.271

[10] Urabe, M., Takakura, T., Metoki, S., Yanagisawa, M., Murata, H.: Mechanism of and Fuel Efficiency Improvement by Dimple Texturing on Liner Surface for Reduction of Friction between Piston Rings and Cylinder Bore, SAE Technical Paper 2014-01-1661(2014), https://doi.org/10.4271/2014-01-1661

[11] Urabe, M., Piston Ring Friction Reduction and Optimizing of Dimple Texture on Cylinder Liner to Contribute to Engine fuel efficiency, LEMA, Vol. 525, pp. 9-13(2016)

[12] Dinkelacker, F., Denkena, B., Rienacker, A., Koeser, P. S.: Tribologisch maßgeschneiderte Zylinderlaufbuchsen durch spanend gefertigte Mikrostrukturen, Abschlussbericht Deutsche Forschungsgemeinschaft (DFG) - Project number 276357669(2019)

[13] Takiguchi, M., Takimoto, T., Asakawa, E., Nakayama, K., Someya, T.: A Study of Friction Force Reduction on Piston Skirt (Effect of Width, Roughness and Resin Coating), Trans. JSME, Vol. 63, No. 611, pp. 327-332(1997) 